\title{
Role of microRNAs in intervertebral disc degeneration (Review)
}

\author{
FENGGUANG YANG ${ }^{*}$, JIZU WANG ${ }^{*}$, ZHIXIN CHEN* ${ }^{*}$, YUPING YANG ${ }^{*}$, \\ WENHUI ZHANG, SHIFANG GUO and QINGSHAN YANG \\ Department of Orthopedics, Gansu Provincial Hospital, Lanzhou, Gansu 730000, P.R. China
}

Received October 23, 2020; Accepted May 19, 2021

DOI: $10.3892 / \mathrm{etm} .2021 .10292$

\begin{abstract}
The incidence of lower back pain caused by intervertebral disc degeneration (IDD) is gradually increasing. IDD not only affects the quality of life of the patients, but also poses a major socioeconomic burden. There is currently no optimal method for delaying or reversing IDD, mainly due to its unknown pathogenesis. MicroRNAs (miRNAs/miRs) participate in the development of a number of diseases, including IDD. Abnormal expression of miRNAs in the intervertebral disc is implicated in various pathological processes underlying the development of IDD, including nucleus pulposus (NP) cell (NPC) proliferation, NPC apoptosis, extracellular matrix remodeling, inflammation and cartilaginous endplate changes, among others. The focus of the present review was the advances in research on the involvement of miRNAs in the mechanism underlying IDD. Further research is expected to identify markers for early diagnosis of IDD and new targets for delaying or reversing IDD.
\end{abstract}

\section{Contents}

\section{Introduction}

2. miRNAs and IDD

3. miRNAs and NPC proliferation

4. miRNAs and NPC apoptosis

5. miRNAs and inflammation

6. miRNAs and ECM remodeling

7. miRNAs and CEP changes

8. miRNAs and AF

9. miRNAs and IDD diagnosis

10. Conclusion

Correspondence to: Dr Qingshan Yang or Dr Shifang Guo, Department of Orthopedics, Gansu Provincial Hospital, Donggang West Road, Lanzhou, Gansu 730000, P.R. China

E-mail: yangqs1555@163.com

E-mail: guosf0208@163.com

*Contributed equally

Key words: microRNA, intervertebral disc degeneration, pathology, proliferation, apoptosis

\section{Introduction}

Intervertebral disc (IVD) degeneration (IDD) is one of the main causes of low back pain (1-3). Low back pain is common, with $\sim 80 \%$ of the population experiencing low back pain at different time points during their lifetime $(4,5)$, and $~ 40 \%$ of all cases are caused by IDD (6). Low back pain caused by IDD costs $\sim 70$ billion euros annually worldwide (7). IDD not only affects the quality of life of the patients, but also poses a major socioeconomic burden. However, there is currently no effective and reliable treatment for IDD, mainly due to its unknown pathogenesis. Reversing or delaying the progression of IDD is particularly important for restoring the original physiological structure and function of the spine.

IDD has been widely considered as the result of 'wear and tear' due to aging and mechanical strain (8), but these factors have limited impact on the IVDs (9), and several studies have found that genetic factors account for $74 \%$ of all cases of IDD (10). MicroRNAs (miRNAs/miRs) are small endogenous non-coding RNAs that regulate gene expression at the post-transcriptional level (11), participating in a number of processes, including cell proliferation, differentiation and apoptosis, among others $(12,13)$. miRNAs have also been closely linked to the process of disc degeneration, with several advances in related research (14-17). The aim of the present review was to focus on the progress of the research on the role of miRNAs in nucleus pulposus (NP) cell (NPC) proliferation and apoptosis, inflammation, extracellular matrix (ECM) remodeling and cartilaginous endplate (CEP) changes, and to discuss the pathogenic mechanisms and potential therapeutic prospects of miRNAs in the treatment of IDD.

\section{2. miRNAs and IDD}

The molecular pathological mechanism of IDD remains largely unclear. However, previous studies have shown that IDD is closely associated with apoptosis, cell proliferation, ECM degradation and inflammation $(18,19)$. There is increasing evidence that miRNAs are involved in several aspects of cellular function, such as proliferation, apoptosis and inflammation, thereby regulating a series of pathophysiological changes that affect a number of processes. Several studies have reported significant changes in miRNA expression in degenerated IVD tissue (20-28), a number of which may be involved in the pathological process of IDD. 


\section{3. miRNAs and NPC proliferation}

Young and healthy human IVDs contain two types of cells: Notochordal cells, which are vacuolated cells originating from the embryonic notochord; and NPCs. NPCs are less dense in healthy human IVDs and have specific distribution areas $(29,30)$. One characteristic of IVD degeneration is the appearance of clusters of cells, particularly in damaged areas (31). The appearance of cell clusters is considered to be the result of abnormal proliferation of NPCs, which is closely associated with IVD degeneration (32). Proliferation is the basic life activity of cells and is affected by a number of factors. miRNAs regulate a variety of physiological activities and pathological processes, including cell proliferation, at the post-transcriptional level $(12,33)$.

miR-21 is one of the most extensively investigated miRNAs. It is expressed in a variety of tissue types (34-36) and is involved in the regulation of cell proliferation (37). The expression of miR-21 in degenerated NP tissue is significantly higher compared with that in healthy NP tissue and is closely associated with the degree of IVD degeneration (14). Moreover, bioinformatics target prediction has indicated that PTEN may be the target of miR-21, that miR-21 inhibits PTEN expression by directly targeting its 3'-untranslated region, and this inhibition is eliminated by miR-21 binding site mutation (14). In addition, miR-21 overexpression-mediated cell proliferation and increased cyclin D1 expression were almost completely blocked by the Akt inhibitor, Ly294002 (14). In conclusion, the abnormal upregulation of miR-21 in IVDs may target PTEN, which is involved in the abnormal proliferation of NPCs through derepressing the Akt pathway (14). This suggests that the miR-21 and PTEN/Akt pathways may be potential targets for inhibiting the abnormal proliferation of NPCs. In addition, miR-21 inhibitors can inhibit the expression of hypoxia-inducible factor- $1 \alpha$ and VEGF in the annulus fibrosus (AF) and NP, and inhibit NPC apoptosis (15). Furthermore, miR-21 may promote the proliferation of NPCs via targeting programmed cell death 4 (16). Upregulation of miR-21 also increases the expression of MMP-2 and MMP-9 mRNA (16). Proteins in the MMP family are classified into three categories based on the degradation substrate: Collagenases (for example, MMP-1 and MMP-13), gelatinases (for example, MMP-2 and MMP-9), which act on denatured collagen and collagen types IV and V, and stromelysins (for example, MMP-3) (17). Therefore, miR-21 not only regulates the number of NPCs, but also regulates in the expression of MMP.

As another potentially important miRNA, miR-10b has not only been found to be expressed in a variety of tissue types, but also has several functions (38), and its abnormal expression is closely associated with the occurrence of malignant tumors dominated by uncontrollable cell proliferation (39). Compared with the NP tissue of patients with idiopathic scoliosis, miR-10b expression in degenerated NP tissues is significantly increased and is closely associated with the degree of disc degeneration (40). In vitro, miR-10b overexpression was shown to stimulate NPC proliferation and inhibit the translation of the homeobox D10 (HOXD10) gene, whereas restored HOXD10 expression reversed the pro-mitotic effect of miR-10b (40). miR-10b-mediated downregulation of HOXD10 expression resulted in increased Ras homolog gene family member $\mathrm{C}$ (RhoC) expression and Akt phosphorylation. By downregulating $\mathrm{RhoC}$ or inhibiting Akt, the effects of miR-10b on NPC proliferation were eliminated (40). This suggests that abnormal upregulation of miR-10b in IDD may result in abnormal proliferation of NPCs by targeting HOXD10 to inhibit the RhoC/Akt pathway.

miR-96 was found to be upregulated in human degenerated NP tissue and was positively correlated with the degree of IDD (41). Overexpression of miR-96 may promote NPC proliferation by targeting AT-rich interaction domain 2 to activate the Akt signaling pathway (41). miR-665 is similar to miR-9 in that its expression increases with the aggravation of disc degeneration. The increased expression of miR-665 not only promotes NPC proliferation, but also reduces aggrecan and type II collagen expression and increases MMP-3 and MMP-13 expression by inhibiting the expression of growth differentiation factor 5 in NPCs (42). miR-125b-1-3p regulates the cell cycle proteins cyclin D1 and B1 by targeting teashirt zinc finger homeobox 3, which may be involved in the regulation of NPC proliferation (43). In addition, miR-184 was elevated in degenerative NP tissues and promoted abnormal proliferation of NPCs via the growth arrest-specific 1/Akt pathway (44). The abnormal proliferation of NPCs is one of the early changes observed in IDD, and some miRNAs are involved in this important pathological change (Table I). Therefore, these miRNAs are expected to represent targets for the early detection and prevention of IDD.

\section{4. miRNAs and NPC apoptosis}

Apoptosis, or programmed cell death, is an important factor in IDD. NPCs are the main source of ECM in IVD tissue. When NPCs become apoptotic, the amount of ECM is reduced, and the water in the IVD tissue cannot be retained, resulting in the loss of biomechanical properties (45). NPC apoptosis is considered to be an important mechanism involved in IDD, and some miRNAs have been reported to be involved in the regulation of apoptosis in NPCs (Table II) (46-64).

A growing body of literature suggests that miR-494 plays an important role in the regulation of apoptosis in NPCs. It has been found that miR-494 is upregulated in degenerated human IVD tissue, and inhibition of miR-494 may protect NPCs from TNF- $\alpha$-induced apoptosis by targeting JunD and cytochrome $c$ (46). In addition, miR-494 promotes the expression of ECM resolution factors, such as MMPs and a disintegrin and metalloproteinase with thrombospondin motifs (ADAMTS), by directly targeting sex-determining region Y-box (SOX)9 and reducing the expression of type II collagen and aggrecan, which mediates the apoptosis of degenerated human NPCs (47). Some scholars have observed elevated miR-494 expression levels in IDD rats, whereas miR-494 inhibitors reduced caspase- 3 and Bax expression, and increased neurooncological ventral antigen 1 (NOVA1) and Bcl-2 expression (48). NOVA1 was identified as a target gene of miR-494 by a dual-luciferase reporter assay (48). miR-494 is widely involved in the apoptosis of NPCs and plays an important role in the progression of IDD. Therefore, it may represent a promising potential target for IDD treatment.

Recent research has found decreased expression of miR-129-5p in human IDD, whereas NPCs treated with 
Table I. miRNAs are involved in NPC proliferation in IDD.

\begin{tabular}{|c|c|c|c|c|c|}
\hline Author (year) & miRNA & Experimental model & Expression & Target & (Refs.) \\
\hline Liu et al, 2014 & miR-21 & hIDD tissue, hNPC & Up & PTEN & (14) \\
\hline Sheng et al, 2018 & miR-21 & Rat IDD model & Up & HIF-1 $\alpha /$ VEGF & $(15)$ \\
\hline Chen et al, 2016 & miR-21 & hNP tissue, hNPC & Up & PDCD4 & $(16)$ \\
\hline Yu et al, 2013 & miR-10b & hIDD tissue, hNPC & Up & HOXD10 & $(40)$ \\
\hline Tao et al, 2017 & $\operatorname{miR}-96$ & hIDD tissue, hNPC & Up & ARID2/AKT & $(41)$ \\
\hline Tan et al, 2018 & miR-665 & hNP tissue, hNPC & Up & GDF5 & $(42)$ \\
\hline Li et al, 2017 & miR-184 & hNP tissue, hNPC & Up & GAS1 & $(44)$ \\
\hline
\end{tabular}

miR/miRNA, microRNA; IDD, intervertebral disk degeneration; h, human; NP, nucleus pulposus; NPC, NP cell; PDCD4, programmed cell death 4; HOXD10, homeobox D10; ARID2, AT-rich interaction domain 2; GDF, growth differentiation factor; GAS1, growth arrest-specific 1.

Table II. miRNAs involved in NPC apoptosis in IDD.

\begin{tabular}{|c|c|c|c|c|c|}
\hline Author (year) & miRNA & Experimental model & Expression & Target & (Refs.) \\
\hline Wang et al, 2015 & miR-494 & hNPC & Up & JunD & (46) \\
\hline Kang et al, 2017 & miR-494 & hNP tissue, $\mathrm{hNPC}$ & Up & SOX9 & $(47)$ \\
\hline Li et al, 2018 & miR-494 & hNPC, rat IDD model & Up & NOVA1 & $(48)$ \\
\hline Yang and Sun, 2019 & miR-129-5p & hIDD tissue, NPC & Down & BMP2 & (49) \\
\hline Sun et al, 2019 & $\operatorname{miR}-499 a-5 p$ & hNPC, hNP tissue & Down & SOX4 & $(50)$ \\
\hline Yang et al, 2019 & miR-143-5p & Rat IDD model, rat NPC & Up & eEF2 & $(51)$ \\
\hline Liu et al, 2017 & $\operatorname{miR}-125 \mathrm{a}$ & hNP tissue, $\mathrm{hNPC}$ & Down & BAK1 & $(52)$ \\
\hline Wang et al, 2011 & miR-155 & hNP tissue, $\mathrm{hNPC}$ & Down & FADD/caspase-3 & $(28)$ \\
\hline Zhao et al, 2017 & miR-143 & hNP tissue, $\mathrm{hNPC}$ & Up & BCL2 & $(54)$ \\
\hline Lv et al, 2018 & miR-30d & hNP tissue, $\mathrm{hNPC}$ & Up & SOX9 & $(55)$ \\
\hline Liu et $a l, 2013$ & $\operatorname{miR}-27 \mathrm{a}$ & $\mathrm{hNP}$ tissue, $\mathrm{hNPC}$ & Up & PI3K & $(56)$ \\
\hline Wang et al, 2016 & miR-138-5p & hNP tissue, $\mathrm{hNPC}$ & Down & SIRT1 & (57) \\
\hline Sun et al, 2018 & miR-532 & hNPC, h-blood & Up & Bcl-9 & $(58)$ \\
\hline Wang et al, 2019 & miR-573 & hNP tissue, $\mathrm{hNPC}$ & Down & Bax & (59) \\
\hline Liu et al, 2016 & $\operatorname{miR}-4458$ & $\mathrm{hNP}$ tissue, $\mathrm{hNPC}$ & Up & IGF1 & $(60)$ \\
\hline Zhang et al, 2016 & $\operatorname{miR}-210$ & hNP tissue hNPC & Down & HOXA9 & (61) \\
\hline Cai et al, 2017 & miR-15a & $\mathrm{hNP}$ tissue, $\mathrm{hNPC}$ & Up & MAP3K9 & $(62)$ \\
\hline Liu et al, 2019 & $\operatorname{miR}-222-3 p$ & hNPC & Up & CDKN1B & (63) \\
\hline Wang et al, 2018 & miR-199 & hNPC & Down & MAP3K5 & (64) \\
\hline
\end{tabular}

miR/miRNA, microRNA; h, human; NP, nucleus pulposus; NPC, NP cell; IDD, intervertebral disk degeneration; SOX, sex-determining region Y-box; HOXA9, homeobox A9; IGF1, insulin-like growth factor 1; CDKN1B, cyclin-dependent kinase inhibitor 1B; NOVA1, neurooncological ventral antigen 1; eEF2, eukaryotic elongation factor 2; BAK1, Bc12 antagonist/killer 1; SIRT, sirtuin; FADD, Fas-associated protein with death domain.

miR-129-5p mimics or bone morphogenic protein 2 (BMP-2) siRNA exhibited improved survival and inhibition of apoptosis (49). Therefore, the abnormal expression of miR-129-5p may serve a role in IDD by targeting BMP-2. Similar to miR-129-5p, miR-499a-5p was also found to be significantly downregulated in human degenerated NP tissue. miR-499a-5p knockout promoted NPC apoptosis, stimulated caspase activation, enhanced MMP-3 and MMP-13 expression, and decreased aggrecan and type II collagen expression (50). In addition, overexpression of miR-499a-5p alleviated the apoptosis of TNF- $\alpha$-treated NPCs and the imbalance of ECM anabolism and catabolism; however, the abnormal expression of SOX4 weakened the negative effect of miR-499a-5p on NPC apoptosis and the positive effect on ECM synthesis (50). This indicates that the effects of miR-499a-5p may be mediated by targeting SOX4. NPCs are the main functional cells of the IVD. The ECM produced by NPCs is the structural basis of the biomechanical properties of the IVD.

Consequently, the abnormal proliferation of NPCs is an early pathological change of IDD (44) and may be helpful for the early identification of IDD. Whether the function of NPCs after early abnormal proliferation is the same as those of the parental NPCs needs further study. The ECM in IVD tissue is mainly derived from NPCs, and the apoptosis of NPCs will 
Table III. miRNAs involved in inflammation in IDD.

\begin{tabular}{|c|c|c|c|c|c|}
\hline Author (year) & miRNA & Experimental model & Expression & Target & (Refs.) \\
\hline Gu et al, 2015 & miR-146a & IL1-NPC (bovine tail) & / & IL-1 & $(69)$ \\
\hline Lv et al, 2017 & miR-146a & PBMCs/LPS-hNPC & Down & IL-1b/IL-6, TNF- $\alpha$ & $(70)$ \\
\hline Chen et al, 2019 & miR-194-5p & hFOB, hAFC, hNPC, hIDD tissue & Down & CUL4A/B & $(71)$ \\
\hline Qin et al, 2019 & miR-149 & LPS-NPC (rat) & Down & MyD88 & $(72)$ \\
\hline Zhang et al, 2019 & $\operatorname{miR}-222$ & hNPC, hIDD tissue & Up & TIMP3 & $(73)$ \\
\hline Sun et al, 2018 & miR-155 & Rat NPC, hNPC, hNP tissue & l & TCF7L2 & $(74)$ \\
\hline Shen et al, 2019 & miR-625-5p & hAFC, hNPC, hIDD tissue & Up & COL1A1 & $(75)$ \\
\hline Lu et al, 2018 & miR-589-3p & hNPC & Up & SMAD4 & $(76)$ \\
\hline Zhang et al, 2018 & $\operatorname{miR}-140-5 p$ & hNPC, hIDD tissue & Down & TLR4 & $(77)$ \\
\hline Dong et al, 2019 & miR-640 & hNPC, hAFC, hIDD tissue & Up & LRP1 & $(78)$ \\
\hline Li et al, 2018 & $\operatorname{miR}-148 \mathrm{a}$ & hNPC, hIDD tissue & Down & p-p38 & (79) \\
\hline Wang et al, 2018 & miR-223 & Rat NP tissues, rat NPC & Down & Irak1 & $(80)$ \\
\hline Kong et al, 2018 & miR-194 & LPS-NPC (rat) & Down & TRAF6 & $(81)$ \\
\hline Zhou et al, 2019 & miR-155 & Rat NPC, C57BL/6 mouse & l & $\mathrm{C} / \mathrm{EBP} \beta$ & $(82)$ \\
\hline Cao and Chen, 2017 & $\operatorname{miR}-27 a$ & hIDD tissue, hNPC & Up & IL-1 $\beta / \mathrm{IL}-6 / \mathrm{TNF}-\alpha$ & $(83)$ \\
\hline
\end{tabular}

miR/miRNA, microRNA; NP, nucleus pulposus; PBMCs, peripheral blood mononuclear cells; LPS, lipopolysaccharide; h, human; FOB, osteoblast cell; AFC, annuls fibrosus cell; NPC, NP cell; IDD, intervertebral disc degeneration; CUL4, cullin family gene 4; MyD88, myeloid differentiation factor 88; TIMP, tissue inhibitor of metalloproteinase; COL1A1, collagen, type I, alpha 1; TLR, toll-like receptor; TCF7L2, transcription factor 7 like 2; LRP1, LDL receptor-related protein-1; Irak1, IL-1 receptor-associated kinase 1; TRAF6, TNFR-associated factor 6; $\mathrm{C} / \mathrm{EBP}, \mathrm{CCAAT} / \mathrm{enhancer}$ binding protein.

accelerate the degeneration of the IVD. Further understanding the association between miRNAs and NPC apoptosis in the process of IDD may provide new approaches to delaying or reversing IDD.

\section{5. miRNAs and inflammation}

Inflammation is considered to be an important mechanism in the IDD process. The concentrations of nitric oxide, prostaglandin E2, IL-1 $\beta$, IL-6 and TNF- $\alpha$ in degenerated IVDs were found to be higher compared with those in normal IVDs (64-66). Furthermore, IL-1 $\beta$ and TNF- $\alpha$ mediate catabolism and anti-anabolism within the NP, which are largely involved in the establishment and progression of IDD $(67,68)$. In recent years, numerous studies (69-83) have revealed that miRNAs may be involved in IDD through the regulation of inflammation (Table III).

miR-146a has been reported to inhibit the mRNA expression of IL-1-mediated inflammatory genes and catabolic proteinases, as well as the protein level of IL-1-mediated MMPs and aggrecanases (69). In 2017, Lv et al (70) demonstrated that the expression of miR-146a in peripheral blood mononuclear cells of patients with IDD was significantly downregulated. In addition, they found that overexpression of miR-146a could significantly downregulate the levels of pro-inflammatory cytokines (IL-1 $\beta$, IL- 6 and TNF- $\alpha$ ) in lipopolysaccharide-stimulated NPCs, and confirmed that these effects depend on the TNF receptor associated-associated factor $6 / \mathrm{NF}-\kappa \mathrm{B}$ pathway.

miR-194-5p was also found to be significantly downregulated in patients with IDD by miRNA-based microarray analysis (71). Inhibition/overexpression of miR-194-5p led to inhibition/overexpression of cullin family (CUL) gene 4A (CUL4A) and CUL4B (71). Furthermore, IL-6 and TNF- $\alpha$ inhibitors in NPCs and AF cells reduced the expression of CUL4A and CUL4B (71). Similar to miR-194-5p, miR-149 was significantly reduced in lipopolysaccharide-induced NPCs (71). Overexpression of miR-149 reversed the expression of aggrecan and collagen II, and alleviated the increase in MMP-3, ADAMTS4 and inflammatory cytokines by targeting myeloid differentiation factor 88 (72). In vitro, miR-222 mimics/inhibitors were able to promote/inhibit NPC apoptosis, respectively (74). Moreover, transfection of miR-222 mimics/inhibitors could significantly increase/reduce the production of TNF- $\alpha$, IL-1 $\beta$, and IL- 6 and inhibit/enhance the expression of collagen II and aggrecan, respectively (73).

Therefore, miRNAs directly or indirectly affect the ECM, NPCs and AF cells of the IVD through the regulation of inflammatory factors, subsequently influencing the process of IDD. Taking specific miRNAs as the entry point to control the progression of inflammation in the process of IDD may be an important approach to delaying the progression of IDD.

\section{6. miRNAs and ECM remodeling}

In human IVDs, the ECM is mainly composed of proteoglycans and type II collagen, which not only retain water, but also help maintain osmotic pressure, thus conferring unique biomechanical properties (84). The balance of ECM catabolism and anabolism is the basis of the biomechanical function of the IVD. An important feature of IDD is that ECM catabolism is greater than its anabolism (85). Recently, a number of studies demonstrated that miRNAs may be involved in the regulation of the ECM in IDD by regulating key molecules (for example, 
Table IV. miRNAs involved in ECM remodeling in IDD.

\begin{tabular}{|c|c|c|c|c|c|}
\hline Author (year) & miRNA & Experimental model & Expression & Target & (Refs.) \\
\hline Ye et al, 2016 & miR-155 & hNPC & Down & ERK1/2 & $(86)$ \\
\hline Zhang et al, 2017 & miR-155 & hIDD & Down & MMP-16 & $(87)$ \\
\hline Jing and Jiang, 2015 & miR-93 & hNP tissue & Down & MMP-3 & $(88)$ \\
\hline Hua et al, 2017 & $\operatorname{miR}-127-5 p$ & hNP tissue & Down & MMP-13 & (89) \\
\hline \multirow[t]{2}{*}{ Yang et al, 2019} & $\operatorname{miR}-483-3 p$ & hNPC & Up & GSK3B & (91) \\
\hline & $\operatorname{miR}-23 c$ & & Down & CTNNB1 & \\
\hline Ji et al, 2016 & miR-98 & hNP tissue & Down & MMP-2 & $(25)$ \\
\hline Zhang et al, 2018 & miR-3150a-3p & hNPC & Up & ACAN & $(92)$ \\
\hline Yan et al, 2015 & miR-100 & hIDD & Up & MMP-13 & (93) \\
\hline Zhou et al, 2017 & miR-146a & hNP tissue & Up & l & (94) \\
\hline Liu et al, 2016 & $\operatorname{miR}-7$ & hNP tissue & Up & GDF5 & $(95)$ \\
\hline Kang et al, 2017 & $\operatorname{miR}-15 b$ & hNP tissue & Up & SMAD3 & (96) \\
\hline Liu et al, 2017 & miR-132 & hNP tissue & Up & GDF5 & (97) \\
\hline Wang et al, 2018 & miR-21 & hNPC & Up & PTEN & (98) \\
\hline Yang et al, 2019 & miR-146 & Rat NPC & l & Notch1 & (99) \\
\hline Shi et al, 2019 & miR-202-3p & hNPC & Down & MMP-1 & $(100)$ \\
\hline Wang et al, 2017 & $\operatorname{miR}-210$ & hNP tissues & Up & ATG7 & $(101)$ \\
\hline Chai et al, 2019 & $\operatorname{miR}-486-5 p$ & LPS-stimulated NPC & Down & FOXO1 & $(102)$ \\
\hline Wang et al, 2019 & miR-154 & hNPC & Up & FGF14 & $(103)$ \\
\hline
\end{tabular}

h, human; NP, nucleus pulposus; NPC, NP cell; IDD, intervertebral disc degeneration; ECM, extracellular matrix; PBMCs, peripheral blood mononuclear cells; LPS, lipopolysaccharide; FOB, osteoblast cell; AFC, annuls fibrosus cell; GSK, glycogen synthase kinase; GDF, growth differentiation factor; CTNNB1, $\beta$-catenin; ACAN, aggrecan; ATG7, autophagy-related gene 7; FOXO1, forkhead box O1; FGF, fibroblast growth factor.

MMPs, collagen II and ADAMTS) that affect anabolic and catabolic processes (25,86-103) (Table IV).

In degenerated disc tissue, inhibition of miR-155 was shown to reduce the expression of collagen II and glycosaminoglycans by targeting ERK1/2 (86). A previous study using an IDD mouse model demonstrated that upregulation of miR-155 upregulated the expression of aggrecan and collagen type II, and downregulated MMP-16 (87), suggesting that miR-155 serves an important regulatory role in ECM anabolism and catabolism.

MMPs are classified into three categories based on the degradation substrate: Collagenases, gelatinases, or stromelysins (37). MMPs are key molecules regulating ECM catabolism. Several miRNAs targeting the MMP family participate in the regulation of ECM metabolism $(18-20,88,89)$. These findings indicate that the involvement of miRNAs in ECM catabolism may be closely associated with the regulation of MMP expression. The effects of MMPs on ECM catabolism and anabolism are important. Therefore, by regulating MMPs, these miRNAs may represent important biological molecules in the alleviation, or even the reversal of ECM loss.

Reversing or alleviating ECM loss is crucial for IDD. Aucubin, a compound found in traditional Chinese medicines, was reported to play a key role in the regulation of the ECM (90). In IDD, the increased release of pro-inflammatory factors by NPCs can cause the degradation of the ECM. However, aucubin can alleviate the degradation of ECM mediated by IL- $1 \beta$ or TNF- $\alpha$ by regulating the miR-140/cAMP responsive element binding protein 1 axis (90). In addition,
Bu Shen Hu Xue Fang (BSHXF), a traditional Chinese medicine, is composed of six herbs (Cortex Eucommiae ulmoides, Fructus Psoraleae, Achyranthes bidentata, Salvia miltiorrhiza, Radix clematidis and Chaenomeles speciosa). Through the regulation of the Wnt signaling pathway by miR-483-3p and miR-23c, BSHXF was shown to affect ECM synthesis and NPC proliferation (91). Thus, traditional Chinese medicine may also be of value in the study of IDD.

\section{7. miRNAs and CEP changes}

The CEP is located between the vertebral endplate and the $\mathrm{NP}$, and is mainly composed of hyaline cartilage cells and chondrocytes, and the ECM they produce. CEP degradation is accompanied by a loss of nutrients in the ECM, which is a major cause for the development of IDD (104). CEP serves as a mechanical shock absorber and is also an important channel for the free transmission of nutrients and metabolites between the avascular NP and the vertebral body (105). It also serves as a barrier and part of the body's defense against toxic and harmful substances, such as inflammatory factors, MMPs and immune molecules, entering the NP $(106,107)$. The occurrence of IDD may be associated with CEP degeneration, dysfunction, and calcification $(108,109)$. Some miRNAs $(110-114)$ have been found to be involved in the changes of the CEP in the progress of IDD (Table V).

Chondrocytes are an important part of the CEP. However, it was demonstrated that upregulation of miR-34a expression 
Table V. miRNAs involved in CEP changes in IDD.

\begin{tabular}{llllll}
\hline Author (year) & miRNA & \multicolumn{1}{c}{ Experimental model } & Expression & Target & (Refs.) \\
\hline Chen et al, 2015 & miR-34a & Chondrocytes (hIDD) & Up & Bcl-2 & $(110)$ \\
Zhan et al, 2018 & miR-625 & hIDD & Down & Fas & $(111)$ \\
Sheng et al, 2018 & miR-221 & Cells (hIDD CEP) & Up & ER $\alpha$ & $(112)$ \\
Zheng et al, 2019 & miR-365 & Chondrocytes (hIDD CEP) & Down & HDAC4 & $(114)$ \\
Liu et al, 2016 & miR-20a & Cells (hCEP) & Up & ANKH & $(116)$ \\
\hline
\end{tabular}

h, human; IDD, intervertebral disc degeneration; CEP, cartilaginous endplate; HDAC, histone deacetylase; ANKH, ankylosis protein homolog; ER, estrogen receptor.

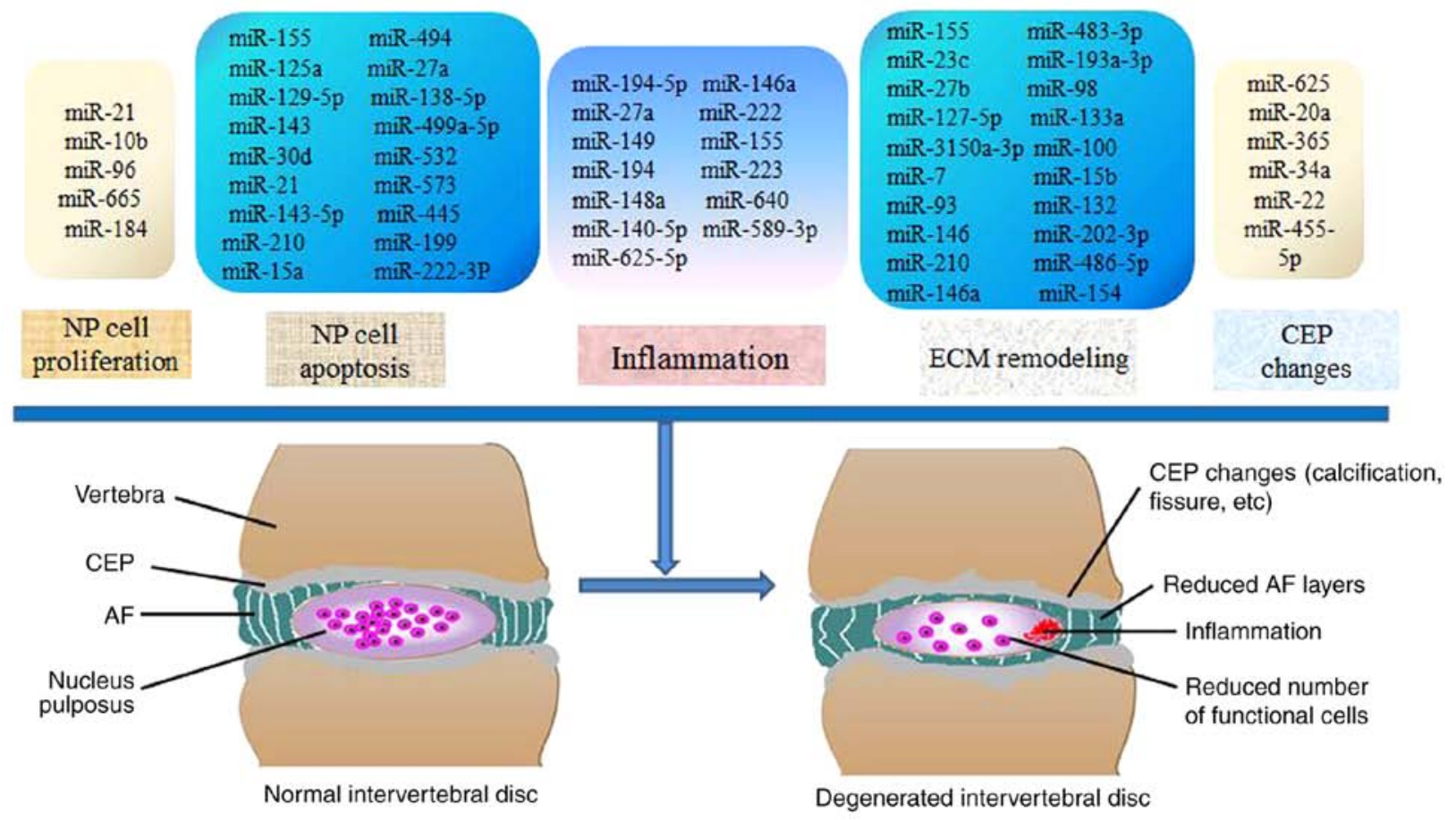

Figure 1. miRNAs promote IDD progression through multiple pathological processes, including NP cell proliferation and apoptosis, inflammation, ECM remodeling and CEP changes. IDD, intervertebral disk degeneration; NP, nucleus pulposus; ECM, extracellular matrix; CEP, cartilaginous endplate; $\mathrm{AF}$, annulus fibrosus; miR/miRNA, microRNA.

in human degenerated chondrocytes caused Fas-mediated CEP chondrocyte apoptosis (110). Similar to miR-34a, downregulation of miR-625 also caused Fas-mediated cervical CEP chondrocyte apoptosis (111). These findings may indicate that the effects of miRNAs on chondrocyte apoptosis in the CEP may be mediated by Fas. Further research may elucidate the role of miRNAs in the apoptosis of CEP chondrocytes.

Interestingly, estrogen (17 $\beta$-estradiol, E2) could inhibit apoptosis of CEP cells and restore cell viability and cell cycle progression in the G0/G1 phase (112). The luciferase assay demonstrated that estrogen receptor $\alpha(\mathrm{ER} \alpha)$ was a target of miR-221 (112). This indicates that miR-221 may affect the protective effect of estrogen on degenerating CEP cells through targeting ER $\alpha$. However, there are few studies on estrogen in IDD, and its specific effect and mechanism require further research.

The CEP is an important load-bearing structure, and long-term mechanical loads are considered to be one of the causes of IDD (113). miR-365 is a mechanically sensitive miRNA, which directly targets histone deacetylase 4 to regulate the degeneration of human chondrocytes (114). In addition, the TGF- $/$ /SMAD signaling pathway inhibits the intermittent cyclic mechanical tension-mediated degeneration of CEP chondrocytes by regulating the miR-455-5p/Runt-related transcription factor 2 (Runx2) axis (115). In addition, it was previously demonstrated that miR-20a/ankylosis protein homolog regulates stiff matrix-promoted CEP calcification (116). Chondrocyte degeneration and calcification affect the function of the CEP, which is an important factor in CEP degeneration.

\section{8. miRNAs and AF}

The AF consists of bundles of fibers arranged in a crisscross pattern and is an important structure surrounding the NP. AF cells may be a source of pluripotent stem cells with the 
potential to differentiate into adipocytes, chondrocytes, neurons, osteoblasts and endothelial cells (117). The normal AF and degenerated AF cells were found to undergo osteogenic differentiation, as shown by mineralization of cultured cells and increased mRNA expression of BMP2, Runx2, alkaline phosphatase and osteocalcin (118). However, the osteogenic differentiation potential of degenerated AF cells is higher than that of normal AF cells, which may be associated with the regulation of the BMP/SMAD pathway by miR-221 (118). AF is an important structure of the IVD. However, the association between pathological changes in the AF and miRNAs in IDD remains elusive.

\section{9. miRNAs and IDD diagnosis}

Early treatment intervention usually improves the outcome of most diseases; however, early diagnosis is a prerequisite for early intervention. There are currently no early diagnostic methods for IDD, and imaging findings are often lacking. Therefore, it is necessary to explore and develop laboratory diagnostic methods for early diagnosis of IDD. The expression level of miR-26a-5p in the serum of mice with IVD degeneration was found to be consistently higher compared with that of young pre-injury samples or a normal control group without IVD degeneration (119). This indicates that miR-26a-5p is a potential molecule for IDD diagnosis. In addition, the expression of miR-146a in peripheral blood mononuclear cells from patients with IDD was significantly lower compared with that of healthy controls (70). Some scholars recently demonstrated that several miRNAs (for example, miR-199a-5p, miR-574-3p, miR-551a and miR-640) may be candidate markers for predicting IDD (120). The clinical correlation between these miRNAs and IDD suggests that miRNAs may be useful as early diagnostic markers of IDD.

\section{Conclusion}

IDD is currently a common disease. However, there is yet no optimal treatment for IDD, and the main reason is that its pathogenesis is unknown. miRNAs participate in the various pathological processes implicated in IDD (Fig. 1). Significant progress has been made in the study of miRNAs affecting the development of IDD, revealing the association between genetic susceptibility and exposure to risk factors, and improving our understanding of the pathogenesis of IDD. Taken together, the findings of the currently available studies highlight miRNAs as a promising research direction for IDD. Further study on the association between miRNAs and IDD may reveal new diagnostic markers and therapeutic targets for IDD.

\section{Acknowledgements}

Not applicable.

\section{Funding}

The present study was supported by the National Natural Science Foundation of China, Regional fund (grant no. 82060409).

\section{Availability of data and materials}

Not applicable.

\section{Authors' contributions}

QY and SG conceived this review article. FY, JW, ZC, YY and WZ searched the literature and collected the articles/published data, for inclusion and interpretation in this review. All the authors were involved in the writing of the manuscript. All the authors have read and approved the final manuscript.

\section{Ethics approval and consent to participate}

Not applicable.

\section{Patient consent for publication}

Not applicable.

\section{Competing interests}

The authors declare that they have no competing interests.

\section{References}

1. Park EH, Moon SW, Suh HR, Hochman S, Lee MG, Kim YI, Jang IT and Han HC: Disc degeneration induces a mechanosensitization of disc afferent nerve fibers that associates with low back pain. Osteoarthritis Cartilage 27: 1608-1617, 2019.

2. Lv B, Yuan J, Ding H, Wan B, Jiang Q, Luo Y, Xu T, Ji P, Zhao Y, Wang L, et al: Relationship between endplate defects, modic change, disc degeneration, and facet joint degeneration in patients with low back pain. Biomed Res Int 2019: 9369853 , 2019.

3. Brinjikji W, Diehn FE, Jarvik JG, Carr CM, Kallmes DF, Murad MH and Luetmer PH: MRI findings of disc degeneration are more prevalent in adults with low back pain than in asymptomatic controls: A systematic review and meta-analysis. AJNR Am J Neuroradiol 36: 2394-2399, 2015.

4. Borenstein D: Mechanical low back pain-a rheumatologist's view. Nat Rev Rheumatol 9: 643-653, 2013.

5. GBD 2016 DALYs and HALE Collaborators: Global, regional, and national disability-adjusted life-years (DALYs) for 333 diseases and injuries and healthy life expectancy (HALE) for 195 countries and territories, 1990-2016: A systematic analysis for the global burden of disease study 2016. Lancet 390: 1260-1344, 2017.

6. Cheung KM, Karppinen J, Chan D, Ho DW, Song YQ, Sham P, Cheah KS, Leong JC and Luk KD: Prevalence and pattern of lumbar magnetic resonance imaging changes in a population study of one thousand forty-three individuals. Spine (Phila Pa 1976) 34: 934-940, 2009.

7. van Uden S, Silva-Correia J, Oliveira JM and Reis RL: Current strategies for treatment of intervertebral disc degeneration: Substitution and regeneration possibilities. Biomater Res 21: 22, 2017.

8. Battié MC, Videman T, Kaprio J, Gibbons LE, Gill K, Manninen H, Saarela J and Peltonen L: The twin spine study: Contributions to a changing view of disc degeneration. Spine J 9: 47-59, 2009.

9. Frymoyer JW: Lumbar disk disease: Epidemiology. Instr Course Lect 41: 217-223,1992.

10. MacGregor AJ, Andrew T, Sambrook PN and Spector TD: Structural, psychological, and genetic influences on low back and neck pain: A study of adult female twins. Arthritis Rheum 51: 160-167, 2004.

11. Bartel DP: MicroRNAs: Target recognition and regulatory functions. Cell 136: 215-233, 2009.

12. Li Z, Lei H, Luo M, Wang Y, Dong L, Ma Y, Liu C, Song W, Wang F, Zhang J, et al: DNA methylation downregulated mir-10b acts as a tumor suppressor in gastric cancer. Gastric Cancer 18: 43-54, 2015. 
13. Zheng F, Liao YJ, Cai MY, Liu YH, Liu TH, Chen SP, Bian XW, Guan XY, Lin MC, Zeng YX, et al: The putative tumour suppressor microRNA-124 modulates hepatocellular carcinoma cell aggressiveness by repressing ROCK 2 and EZH2. Gut 61 : 278-289, 2012.

14. Liu H, Huang X, Liu X, Xiao S, Zhang Y, Xiang T, Shen X, Wang $G$ and Sheng B: miR-21 promotes human nucleus pulposus cell proliferation through PTEN/AKT signaling. Int J Mol Sci 15 4007-4018, 2014.

15. Sheng X, Guo Q, Yu J and Xu Y: Experimental research on the effect of microRNA-21 inhibitor on a rat model of intervertebral disc degeneration. Exp Ther Med 16: 67-72, 2018.

16. Chen B, Huang SG, Ju L, Li M, Nie FF, Zhang Y, Zhang YH, Chen X and Gao F: Effect of microRNA-21 on the proliferation of human degenerated nucleus pulposus by targeting programmed cell death 4. Braz J Med Biol Res 49: e5020, 2016.

17. Millward-Sadler SJ, Costello PW, Freemont AJ and Hoyland JA: Regulation of catabolic gene expression in normal and degenerate human intervertebral disc cells: Implications for the pathogenesis of intervertebral disc degeneration. Arthritis Res Ther 11: R65, 2009.

18. Battié MC, Videman T and Parent E: Lumbar disc degeneration: Epidemiology and genetic influences. Spine (Phila Pa 1976) 29 2679-2690, 2004

19. Cheng X, Zhang L, Zhang K, Zhang G, Hu Y, Sun X, Zhao C, $\mathrm{Li} \mathrm{H}, \mathrm{Li}$ YM and Zhao J: Circular RNA VMA21 protects against intervertebral disc degeneration through targeting miR-200c and X linked inhibitor-of-apoptosis protein. Ann Rheum Dis 77: 770-779, 2018.

20. Feng C, Liu M, Fan X, Yang M, Liu H and Zhou Y: Intermittent cyclic mechanical tension altered the microRNA expression profile of human cartilage endplate chondrocytes. Mol Med Rep 17: 5238-5246, 2018

21. Cheng X, Zhang G, Zhang L, Hu Y, Zhang K, Sun X, Zhao C, Li H, Li YM and Zhao J: Mesenchymal stem cells deliver exogenous miR-21 via exosomes to inhibit nucleus pulposus cell apoptosis and reduce intervertebral disc degeneration. J Cell Mol Med 22: 261-276, 2018

22. Xu YQ, Zhang ZH, Zheng YF and Feng SQ: Dysregulated miR-133a mediates loss of type II collagen by directly targeting matrix metalloproteinase 9 (MMP9) in human intervertebral disc degeneration. Spine (Phila Pa 1976) 41: E717-E724, 2016.

23. Li HR, Cui Q, Dong ZY, Zhang JH, Li HQ and Zhao L: Downregulation of miR-27b is involved in loss of type II collagen by directly targeting matrix metalloproteinase 13 (MMP13) in human intervertebral disc degeneration. Spine (Phila Pa 1976) 41: E116-E123, 2016.

24. Ji ML, Zhang XJ, Shi PL, Lu J, Wang SZ, Chang Q, Chen H and Wang C: Downregulation of microRNA-193a-3p is involved in invertebral disc degeneration by targeting MMP14. J Mol Med (Berl) 94: 457-468, 2016.

25. Ji ML, Lu J, Shi PL, Zhang XJ, Wang SZ, Chang Q, Chen $\mathrm{H}$ and Wang C: Dysregulated miR-98 contributes to extracellular matrix degradation by targeting IL-6/STAT3 signaling pathway in human intervertebral disc degeneration. J Bone Miner Res 31: 900-909, 2016

26. Zhao B, Yu Q, Li H, Guo X and He X: Characterization of microRNA expression profiles in patients with intervertebral disc degeneration. Int J Mol Med 33: 43-50, 2014.

27. Ohrt-Nissen S, Døssing KB, Rossing M, Lajer C, Vikeså J, Nielsen FC, Friis-Hansen L and Dahl B: Characterization of miRNA expression in human degenerative lumbar disks. Connect Tissue Res 54: 197-203, 2013.

28. Wang HQ, Yu XD, Liu ZH, Cheng X, Samartzis D, Jia LT, Wu SX, Huang J, Chen J and Luo ZJ: Deregulated miR-155 promotes Fas-mediated apoptosis in human intervertebral disc degeneration by targeting FADD and caspase-3. J Pathol 225 : 232-242, 2011

29. Fontana G, See E and Pandit A: Current trends in biologics delivery to restore intervertebral disc anabolism. Adv Drug Deliv Rev 84: 146-158, 2015.

30. Maroudas A, Stockwell RA, Nachemson A and Urban J: Factors involved in the nutrition of the human lumbar intervertebral disc: Cellularity and diffusion of glucose in vitro. J Anat 120: 113-130, 1975.

31. Mern DS, Beierfuß A, Thomé C and Hegewald AA: Enhancing human nucleus pulposus cells for biological treatment approaches of degenerative intervertebral disc diseases: A systematic review. J Tissue Eng Regen Med 8: 925-936, 2014.
32. Johnson WE, Eisenstein SM and Roberts S: Cell cluster formation in degenerate lumbar intervertebral discs is associated with increased disc cell proliferation. Connect Tissue Res 42: 197-207, 2001.

33. Araldi E, Chamorro-Jorganes A, van Solingen C, FernandezHernando $C$ and Suarez Y: Therapeutic potential of modulating microRNAs in atherosclerotic vascular disease. Curr Vasc Pharmacol 13: 291-304, 2015

34. Toiyama Y, Takahashi M, Hur K, Nagasaka T, Tanaka K, Inoue Y, Kusunoki M, Boland CR and Goel A: Serum miR-21 as a diagnostic and prognostic biomarker in colorectal cancer. J Natl Cancer Inst 105: 849-859, 2013.

35. Vicinus B, Rubie C, Stegmaier N, Frick VO, Kölsch K, Kauffels A, Ghadjar P, Wagner M and Glanemann M: miR-21 and its target gene CCL20 are both highly overexpressed in the microenvironment of colorectal tumors: Significance of their regulation. Oncol Rep 30: 1285-1292, 2013.

36. Wang P, Zhuang L, Zhang J, Fan J, Luo J, Chen H, Wang K, Liu L, Chen Z and Meng Z: The serum miR-21 level serves as a predictor for the chemosensitivity of advanced pancreatic cancer, and miR-21 expression confers chemoresistance by targeting FasL. Mol Oncol 7: 334-345, 2013.

37. Zhang YX, Yue Z, Wang PY, Li YJ, Xin JX, Pang M, Zheng QY and Xie SY: Cisplatin upregulates MSH2 expression by reducing miR-21 to inhibit A549 cell growth. Biomed Pharmacother 67: 97-102, 2013.

38. Ma L, Teruya-Feldstein $\mathrm{J}$ and Weinberg RA: Tumour invasion and metastasis initiated by microRNA-10b in breast cancer. Nature 449: 682-688, 2007.

39. Zhao FL, Hu GD, Wang XF, Zhang XH, Zhang YK and Yu ZS Serum overexpression of microRNA-10b in patients with bone metastatic primary breast cancer. J Int Med Res 40: 859-866, 2012.

40. Yu X, Li Z, Shen J, Wu WK, Liang J, Weng X and Qiu G: MicroRNA-10b promotes nucleus pulposus cell proliferation through RhoC-Akt pathway by targeting HOXD10 in intervetebral disc degeneration. PLoS One 8: e83080, 2013.

41. Tao B, Yi J, Huang C, Xu W, Qin C, Chen L, Chen J, Gao Y and Wang R: microRNA-96 regulates the proliferation of nucleus pulposus cells by targeting ARID2/AKT signaling. Mol Med Rep 16: 7553-7560, 2017.

42. Tan H, Zhao L, Song R, Liu Y and Wang L: microRNA-665 promotes the proliferation and matrix degradation of nucleus pulposus through targeting GDF5 in intervertebral disc degeneration. J Cell Biochem 119: 7218-7225, 2018.

43. Meng X, Zhu Y, Tao L, Zhao S and Qiu S: MicroRNA-125b-1-3p mediates intervertebral disc degeneration in rats by targeting teashirt zinc finger homeobox 3. Exp Ther Med 15: 2627-2633, 2018.

44. Li W, Wang P, Zhang Z, Wang W, Liu Y and Qi Q: MiR-184 regulates proliferation in nucleus pulposus cells by targeting GAS1. World Neurosurg 97: 710-715.e1, 2017.

45. Heuer F, Schmidt $\mathrm{H}$ and Wilke HJ: The relation between intervertebral disc bulging and annular fiber associated strains for simple and complex loading. J Biomech 41: 1086-1094, 2008.

46. Wang T, Li P, Ma X, Tian P, Han C, Zang J, Kong J and Yan H: MicroRNA-494 inhibition protects nucleus pulposus cells from TNF- $\alpha$-induced apoptosis by targeting JunD. Biochimie 115: 1-7, 2015.

47. Kang L, Yang C, Song Y, Zhao K, Liu W, Hua W, Wang K, Tu J, Li S, Yin H and Zhang Y: MicroRNA-494 promotes apoptosis and extracellular matrix degradation in degenerative human nucleus pulposus cells. Oncotarget 8: 27868-27881, 2017.

48. Li L, Zhang L and Zhang Y: Roles of miR-494 in intervertebral disk degeneration and the related mechanism. World Neurosurg, Dec 30, 2018 (Online ahead of print).

49. Yang W and Sun P: Downregulation of microRNA-129-5p increases the risk of intervertebral disc degeneration by promoting the apoptosis of nucleus pulposus cells via targeting BMP2. J Cell Biochem 120: 19684-19690, 2019.

50. Sun JC, Zheng B, Sun RX, Meng YK, Wang SM, Yang HS, Chen Y, Shi JG and Guo YF: MiR-499a-5p suppresses apoptosis of human nucleus pulposus cells and degradation of their extracellular matrix by targeting SOX4. Biomed Pharmacother 113: 108652, 2019

51. Yang Q, Guo XP, Cheng YL and Wang Y: MicroRNA-143-5p targeting eEF2 gene mediates intervertebral disc degeneration through the AMPK signaling pathway. Arthritis Res Ther 21: 97 , 2019.

52. Liu P, Chang F, Zhang T, Gao G, Yu C, Ding SQ, Zuo GL and Huang XH: Downregulation of microRNA-125a is involved in intervertebral disc degeneration by targeting pro-apoptotic Bcl-2 antagonist killer 1. Iran J Basic Med Sci 20: 1260-1267, 2017. 
53. Ma JF, Zang LN, Xi YM, Yang WJ and Zou D: MiR-125a Rs12976445 polymorphism is associated with the apoptosis status of nucleus pulposus cells and the risk of intervertebral disc degeneration. Cell Physiol Biochem 38: 295-305, 2016.

54. Zhao K, Zhang Y, Kang L, Song Y, Wang K, Li S, Wu X, Hua W, Shao Z, Yang S and Yang C: Epigenetic silencing of miRNA-143 regulates apoptosis by targeting BCL2 in human intervertebral disc degeneration. Gene 628: 259-266, 2017.

55. Lv J, Li S, Wan T, Yang Y, Cheng Y and Xue R: Inhibition of microRNA-30d attenuates the apoptosis and extracellular matrix degradation of degenerative human nucleus pulposus cells by up-regulating SOX9. Chem Biol Interact 296: 89-97, 2018.

56. Liu G, Cao P, Chen H, Yuan W, Wang J and Tang X: MiR-27a regulates apoptosis in nucleus pulposus cells by targeting PI3K. PLoS One 8: e75251, 2013.

57. Wang B, Wang D, Yan T and Yuan H: MiR-138-5p promotes TNF- $\alpha$-induced apoptosis in human intervertebral disc degeneration by targeting SIRT1 through PTEN/PI3K/Akt signaling. Exp Cell Res 345: 199-205, 2016.

58. Sun Z, Jian Y, Fu H and Li B: MiR-532 downregulation of the Wnt/ $\beta$-catenin signaling via targeting Bcl-9 and induced human intervertebral disc nucleus pulposus cells apoptosis. J Pharmacol Sci 138: 263-270, 2018.

59. Wang R, Wen B and Sun D: miR-573 regulates cell proliferation and apoptosis by targeting Bax in nucleus pulposus cells. Cell Mol Biol Lett 24: 2,2019.

60. Liu ZQ, Fu WQ, Zhao S and Zhao X: Regulation of insulin-like growth factor 1 receptor signaling by microRNA-4458 in the development of lumbar disc degeneration. Am J Transl Res 8: 2309-2316, 2016.

61. Zhang DY, Wang ZJ, Yu YB, Zhang Y and Zhang XX: Role of microRNA-210 in human intervertebral disc degeneration. Exp Ther Med 11: 2349-2354, 2016.

62. Cai P, Yang T, Jiang X, Zheng M, Xu G and Xia J: Role of miR-15a in intervertebral disc degeneration through targeting MAP3K9. Biomed Pharmacother 87: 568-574, 2017.

63. Liu J, Yu J, Jiang W, He M and Zhao J: Targeting of CDKN1B by miR-222-3p may contribute to the development of intervertebral disc degeneration. FEBS Open Bio 9: 728-735, 2019

64. Wang W, Guo Z, Yang S, Wang H and Ding W: Upregulation of miR-199 attenuates TNF- $\alpha$-induced Human nucleus pulposus cell apoptosis by downregulating MAP3K5. Biochem Biophys Res Commun 505: 917-924, 2018.

65. Kang JD, Georgescu HI, McIntyre-Larkin L, Stefanovic-Racic M Donaldson WF III and Evans CH: Herniated lumbar intervertebral discs spontaneously produce matrix metalloproteinases, nitric oxide, interleukin-6, and prostaglandin E2. Spine (Phila Pa 1976) 21 271-277, 1996.

66. Séguin CA, Pilliar RM, Roughley PJ and Kandel RA: Tumor necrosis factor-alpha modulates matrix production and catabolism in nucleus pulposus tissue. Spine (Phila $\mathrm{Pa}$ 1976) 30 : 1940-1948, 2005.

67. Ohba T, Haro H, Ando T, Wako M, Suenaga F, Aso Y, Koyama K, Hamada Y and Nakao A: TNF-alpha-induced NF-kappaB signaling reverses age-related declines in VEGF induction and angiogenic activity in intervertebral disc tissues. J Orthop Res 27: 229-235, 2009.

68. Clouet J, Vinatier C, Merceron C, Pot-Vaucel M, Hamel O, Weiss P, Grimandi $\mathrm{G}$ and Guicheux J: The intervertebral disc: From pathophysiology to tissue engineering. Joint Bone Spine 76: 614-618, 2009.

69. Gu SX, Li X, Hamilton JL, Chee A, Kc R, Chen D, An HS Kim JS, Oh CD, Ma YZ, et al: MicroRNA-146a reduces IL-1 dependent inflammatory responses in the intervertebral disc. Gene 555: 80-87, 2015.

70. LvF, Huang Y,Lv W, Yang L,Li F, Fan J and Sun J: MicroRNA-146a Ameliorates inflammation via TRAF6/NF- $\kappa$ B pathway in intervertebral disc cells. Med Sci Monit 23: 659-664, 2017.

71. Chen Z, Han Y, Deng C, Chen W, Jin L, Chen H, Wang K, Shen $\mathrm{H}$ and Qian L: Inflammation-dependent downregulation of miR-194-5p contributes to human intervertebral disc degeneration by targeting CUL4A and CUL4B. J Cell Physiol 234 19977-19989, 2019.

72. Qin C, Lv Y, Zhao H, Yang B and Zhang P: MicroRNA-149 suppresses inflammation in nucleus pulposus cells of intervertebra discs by regulating MyD88. Med Sci Monit 25: 4892-4900, 2019.

73. Zhang Y, Yang J, Zhou X, Wang N, Li Z, Zhou Y, Feng J, Shen D and Zhao W: Knockdown of miR-222 inhibits inflammation and the apoptosis of LPS-stimulated human intervertebral disc nucleus pulposus cells. Int J Mol Med 44: 1357-1365, 2019.
74. Sun J, Hong J, Sun S, Wang X, Peng Y, Zhou J, Huang Y, Li S, Chen W, Li C, et al: Transcription factor 7-like 2 controls matrix degradation through nuclear factor $\kappa \mathrm{B}$ signaling and is repressed by microRNA-155 in nucleus pulposus cells. Biomed Pharmacother 108: 646-655, 2018.

75. Shen L, Xiao Y, Wu Q, Liu L, Zhang C and Pan X: TLR4/NF- $\kappa B$ axis signaling pathway-dependent up-regulation of miR-625-5p contributes to human intervertebral disc degeneration by targeting COL1A1. Am J Transl Res 11: 1374-1388, 2019.

76. Lu A, Wang Z and Wang S: Role of miR-589-3p in human lumbar disc degeneration and its potential mechanism. Exp Ther Med 15: $1616-1621,2018$

77. Zhang Q, Weng Y, Jiang Y, Zhao S, Zhou D and Xu N: Overexpression of miR-140-5p inhibits lipopolysaccharide-induced human intervertebral disc inflammation and degeneration by downregulating toll-like receptor 4 . Oncol Rep 40: 793-802, 2018.

78. Dong W, Liu J, Lv Y, Wang F, Liu T, Sun S, Liao B, Shu Z and Qian J: miR-640 aggravates intervertebral disc degeneration via NF- $\kappa B$ and WNT signalling pathway. Cell Prolif 52: e12664, 2019.

79. Li G, Tang X, Chen H, Sun W and Yuan F: miR-148a inhibits pro-inflammatory cytokines released by intervertebral disc cells by regulating the p38/MAPK pathway. Exp Ther Med 16: 2665-2669, 2018

80. Wang H, Hao P, Zhang H, Xu C and Zhao J: MicroRNA-223 inhibits lipopolysaccharide-induced inflammatory response by directly targeting Irak1 in the nucleus pulposus cells of intervertebral disc. IUBMB Life 70: 479-490, 2018.

81. Kong L, Sun M, Jiang Z, Li L and Lu B: MicroRNA-194 inhibits lipopolysaccharide-induced inflammatory response in nucleus pulposus cells of the intervertebral disc by targeting TNF receptor-associated factor 6 (TRAF6). Med Sci Monit 24: 3056-3067, 2018

82. Zhou J, Liang A, Hong J, Sun J, Lin X, Peng Y, Wang X, Sun S, Xiao D, Xu K and Ye W: MicroRNA-155 suppresses the catabolic effect induced by TNF- $\alpha$ and IL-1 $1 \beta$ by targeting C/EBP $\beta$ in rat nucleus pulposus cells. Connect Tissue Res 60: 165-177, 2019.

83. Cao Z and Chen L: Inhibition of miR-27a suppresses the inflammatory response via the p38/MAPK pathway in intervertebral disc cells. Exp Ther Med 14: 4572-4578, 2017.

84. Yang $X$ and Li X: Nucleus pulposus tissue engineering: A brief review. Eur Spine J 18: 1564-1572, 2009.

85. Le Maitre CL, Pockert A,Buttle DJ, Freemont AJ and Hoyland JA: Matrix synthesis and degradation in human intervertebral disc degeneration. Biochem Soc Trans 35: 652-655, 2007.

86. Ye D, Dai L, Yao Y, Qin S, Xie H, Wang W and Liang W: miR-155 inhibits nucleus pulposus cells' degeneration through targeting ERK 1/2. Dis Markers 2016: 6984270, 2016.

87. Zhang WL, Chen YF, Meng HZ, Du JJ, Luan GN, Wang HQ, Yang MW and Luo ZJ: Role of miR-155 in the regulation of MMP-16 expression in intervertebral disc degeneration. J Orthop Res 35: 1323-1334, 2017.

88. Jing W and Jiang W: MicroRNA-93 regulates collagen loss by targeting MMP3 in human nucleus pulposus cells. Cell Prolif 48 284-292, 2015

89. Hua WB, Wu XH, Zhang YK, Song Y, Tu J, Kang L, Zhao KC, Li S, Wang K, Liu W, et al: Dysregulated miR-127-5p contributes to type II collagen degradation by targeting matrix metalloproteinase-13 in human intervertebral disc degeneration. Biochimie 139: 74-80, 2017.

90. Yang S, Li L, Zhu L, Zhang C, Li Z, Guo Y, Nie Y and Luo Z: Aucubin inhibits IL-1 $\beta$ - or TNF- $\alpha$-induced extracellular matrix degradation in nucleus pulposus cell through blocking the miR-140-5p/CREB1 axis. J Cell Physiol 234: 13639-13648, 2019.

91. Yang S, Li L, Zhu L, Zhang C, Li Z, Guo Y, Nie Y and Luo Z $\mathrm{Bu}-$ Shen-Huo-Xue-Fang modulates nucleus pulposus cell proliferation and extracellular matrix remodeling in intervertebral disk degeneration through miR-483 regulation of Wnt pathway. J Cell Biochem 120: 19318-19329, 2019.

92. Zhang B, Guo W, Sun C, Duan HQ, Yu BB, Mu K, Guan YY, Li Y, Liu S, Liu Y, et al: Dysregulated MiR-3150a-3p promotes lumbar intervertebral disc degeneration by targeting aggrecan. Cell Physiol Biochem 45: 2506-2515, 2018.

93. Yan N, Yu S, Zhang $\mathrm{H}$ and Hou T: Lumbar disc degeneration is facilitated by MiR-100-mediated FGFR3 suppression. Cell Physiol Biochem 36: 2229-2236, 2015.

94. Zhou T, Lin H, Cheng Z, Ji C, Zhang C and Tian J: Mechanism of microRNA-146a-mediated IL-6/STAT3 signaling in lumbar intervertebral disc degeneration. Exp Ther Med 14: 1131-1135, 2017. 
95. Liu W, Zhang Y, Xia P, Li S, Feng X, Gao Y, Wang K, Song Y, Duan Z, Yang S, et al: MicroRNA-7 regulates IL-1 $\beta$-induced extracellular matrix degeneration by targeting GDF5 in human nucleus pulposus cells. Biomed Pharmacother 83: 1414-1421, 2016.

96. Kang L, Yang C, Yin H, Zhao K, Liu W, Hua W, Wang K, Song Y, Tu J, Li S, et al: MicroRNA-15b silencing inhibits IL-1 $\beta$-induced extracellular matrix degradation by targeting SMAD3 in human nucleus pulposus cells. Biotechnol Lett 39: 623-632, 2017.

97. Liu W, Xia P, Feng J, Kang L, Huang M, Wang K, Song Y, Li S, Wu X, Yang S and Yang C: MicroRNA-132 upregulation promotes matrix degradation in intervertebral disc degeneration. Exp Cell Res 359: 39-49, 2017.

98. Wang WJ, Yang W, Ouyang ZH, Xue JB, Li XL, Zhang J, He WS, Chen WK, Yan YG and Wang C: MiR-21 promotes ECM degradation through inhibiting autophagy via the PTEN/akt/mTOR signaling pathway in human degenerated NP cells. Biomed Pharmacother 99: 725-734, 2018.

99. Yang RS, Wang YH, Ding C, Su XH and Gong XB: MiR-146 regulates the repair and regeneration of intervertebral nucleus pulposus cells via Notch1 pathway. Eur Rev Med Pharmacol Sci 23: 4591-4598, 2019.

100. Shi C, Wu L, Lin W, Cai Y,Zhang Y, Hu B, Gao R, Im HJ, Yuan W, Ye X, et al: MiR-202-3p regulates interleukin-1 $\beta$-induced expression of matrix metalloproteinase 1 in human nucleus pulposus. Gene 687: 156-165, 2019.

101. Wang C, Zhang ZZ, Yang W, Ouyang ZH, Xue JB, Li XL, Zhang J, Chen WK, Yan YG and Wang WJ: MiR-210 facilitates ECM degradation by suppressing autophagy via silencing of ATG7 in human degenerated NP cells. Biomed Pharmacother 93: 470-479, 2017

102. Chai X, Si H, Song J, Chong Y, Wang J and Zhao G: miR-486-5p inhibits inflammatory response, matrix degradation and apoptosis of nucleus pulposus cells through directly targeting FOXO1 in intervertebral disc degeneration. Cell Physiol Biochem 52: 109-118, 2019

103. Wang J, Liu X, Sun B, Du W, Zheng Y and Sun Y: Upregulated miR-154 promotes ECM degradation in intervertebral disc degeneration. J Cell Biochem: Mar 1, 2019 (Epub ahead of print). doi: 10.1002/jcb.28471.

104. Grunhagen T, Wilde G, Soukane DM, Shirazi-Adl SA and Urban JP: Nutrient supply and intervertebral disc metabolism. J Bone Joint Surg Am 88 (Suppl 2): S30-S35, 2006.

105. Huang YC, Urban JP and Luk KD: Intervertebral disc regeneration: Do nutrients lead the way? Nat Rev Rheumatol 10: 561-566, 2014

106. Moon SM, Yoder JH, Wright AC, Smith LJ, Vresilovic EJ and Elliott DM: Evaluation of intervertebral disc cartilaginous endplate structure using magnetic resonance imaging. Eur Spine J 22: 1820-1828, 2013.

107. Urban JP, Smith S and Fairbank JC: Nutrition of the intervertebral disc. Spine (Phila Pa 1976) 29: 2700-2709, 2004
108. Ariga K, Miyamoto S, Nakase T, Okuda S, Meng W, Yonenobu K and Yoshikawa $\mathrm{H}$ : The relationship between apoptosis of endplate chondrocytes and aging and degeneration of the intervertebral disc. Spine (Phila Pa 1976) 26: 2414-2420, 2001.

109. Holm S, Holm AK, Ekström L, Karladani A and Hansson T: Experimental disc degeneration due to endplate injury. J Spinal Disord Tech 17: 64-71, 2004.

110. Chen H, Wang J,Hu B, Wu X, Chen Y, Li R and Yuan W: MiR-34a promotes Fas-mediated cartilage endplate chondrocyte apoptosis by targeting Bcl-2. Mol Cell Biochem 406: 21-30, 2015.

111. Zhan B, Zhan Y, Wang W, Zhan Y and Liu B: Expression of miR-625 and Fas in cervical vertebral cartilage endplate. Exp Ther Med 15: 513-519, 2018.

112. Sheng B, Yuan Y, Liu X, Zhang Y, Liu H, Shen X, Liu B and Chang L: Protective effect of estrogen against intervertebral disc degeneration is attenuated by miR-221 through targeting estrogen receptor $\alpha$. Acta Biochim Biophys Sin (Shanghai) 50: 345-354, 2018

113. Stokes IA and Iatridis JC: Mechanical conditions that accelerate intervertebral disc degeneration: Overload versus immobilization. Spine (Phila Pa 1976) 29: 2724-2732, 2004.

114. Zheng Q, Li XX, Xiao L, Shao S, Jiang H, Zhang XL, Sun LY and Xu HG: MicroRNA-365 functions as a mechanosensitive microRNA to inhibit end plate chondrocyte degeneration by targeting histone deacetylase 4. Bone 128: 115052, 2019.

115. Xiao L, Xu S, Xu Y,Liu C, Yang B, Wang J and Xu H: TGF-3/SMAD signaling inhibits intermittent cyclic mechanical tension-induced degeneration of endplate chondrocytes by regulating the miR-455-5p/RUNX2 axis. J Cell Biochem 119: 10415-10425, 2018

116. Liu MH, Sun C, Yao Y, Fan X, Liu H, Cui YH, Bian XW, Huang B and Zhou Y: Matrix stiffness promotes cartilage endplate chondrocyte calcification in disc degeneration via miR-20a targeting ANKH expression. Sci Rep 6: 25401, 2016.

117. Feng G, Yang X, Shang H, Marks IW, Shen FH, Katz A, Arlet V, Laurencin CT and Li X: Multipotential differentiation of human anulus fibrosus cells: An in vitro study. J Bone Joint Surg Am 92: 675-685, 2010

118. Yeh CH, Jin L, Shen F, Balian G and Li XJ: miR-221 attenuates the osteogenic differentiation of human annulus fibrosus cells. Spine J 16: 896-904, 2016.

119. Fan Y, Zhao L, Xie W, Yi D, He S, Chen D and Huang J: Serum miRNAs are potential biomarkers for the detection of disc degeneration, among which miR-26a-5p suppresses Smad1 to regulate disc homeostasis. J Cell Mol Med 23: 6679-6689, 2019.

120. Sherafatian M, Abdollahpour HR, Ghaffarpasand F, Yaghmaei S Azadegan M and Heidari M: MicroRNA expression profiles, target genes, and pathways in intervertebral disk degeneration: A meta-analysis of 3 microarray studies. World Neurosurg 126: 389-397, 2019

This work is licensed under a Creative Commons Attribution-NonCommercial-NoDerivatives 4.0 International (CC BY-NC-ND 4.0) License. 